\title{
Effect of cold exposure on energy balance and liver respiratory capacity in post-weaning rats fed a high-fat diet
}

\author{
Susanna Iossa, Lillà Lionetti, Maria P. Mollica, Raffaella Crescenzo, Antonio Barletta \\ and Giovanna Liverini* \\ Department of General and Environmental Physiology, University of Naples 'FEDERICO II', Italy
}

(Received 1 December 1999 - Revised 20 June 2000 - Accepted 28 June 2000)

\begin{abstract}
Variations in energy balance, body composition, and nutrient partitioning induced by high-fat feeding, cold exposure or by concomitant high-fat feeding and cold exposure were studied in young Wistar rats. Changes in hepatic metabolism as well as in serum free triiodothyronine and leptin levels were also evaluated. Rats were exposed to either 24 or $4^{\circ} \mathrm{C}$ and fed either a low- or high-fat diet $(10 \%$ or $50 \%$ energy respectively) for 2 weeks. Relative to low-fat feeding at $24^{\circ} \mathrm{C}$, both energy intake and expenditure were increased by high-fat feeding or by cold exposure, and these changes were accompanied by increased serum triiodothyronine levels. In response to concomitant high-fat feeding and cold exposure, serum triiodothyronine tended to be further elevated, but no further increases in energy intake or energy expenditure were observed. Independently of diet, the increased energy expenditure in cold-exposed rats was not completely balanced by adaptive hyperphagia, with consequential reductions in protein and fat gain, accompanied by marked decreases in serum leptin. Furthermore, unlike high-fat feeding at $24^{\circ} \mathrm{C}$, cold exposure enhanced hepatic mitochondrial oxidative capacity both in the low-fat- and high-fat-fed groups. It is concluded that in this strain of young Wistar rats, despite similarly marked stimulation of energy expenditure by high-fat feeding at $24^{\circ} \mathrm{C}$, by cold exposure and by concomitant high-fat feeding and cold exposure, an increased hepatic oxidative capacity occurred only in the presence of the cold stimulus.
\end{abstract}

Body composition: Nutrient partitioning: Triiodothyronine: Leptin

Energy balance, which is the difference between energy intake and energy expenditure, is influenced by environmental stimuli such as cold exposure or chronic dietary excess. In fact, it has been shown that an increase in energy intake due to a high-fat diet may stimulate energy expenditure in rats in order to avoid obesity development (Rothwell \& Stock, 1979, 1982; Lionetti et al. 1996a,b; Iossa et al. 1997). However, this obesity resistance depends on the amount and nature of fatty acids in the diet (Hansen et al. 1997; Iossa et al. 2000), as well as on the age of the rats (Widdowson et al. 1997; Iossa et al. 1999, 2000). Exposure to cold, which is a stimulus that increases energy expenditure to maintain body temperature, also induces an increase in energy intake (Luz \& Griggio, 1987; Bing et al. 1998). However, to our knowledge, a complete study on the modifications of energy balance, body composition and nutrient partitioning induced by the combination of cold exposure and high-fat feeding has not yet been carried out. We therefore considered it of interest to study these variables in rats fed a high-fat diet in a cold environment $\left(4^{\circ} \mathrm{C}\right)$ for 2 weeks. To this purpose, full energy balance measurements were carried out. Experiments were made using post-weaning rats, which exhibit high growth velocity and high thermogenic capacity and could, therefore, be more sensitive to the environmental stimuli described earlier. Taking into account that some possible determinants of energy intake and energy expenditure include free triiodothyronine $\left(\mathrm{T}_{3}\right)$ and leptin (Danforth \& Burger, 1989; Freake \& Oppenheimer, 1995; Friedman \& Halaas, 1998), variations in serum free $\mathrm{T}_{3}$ and leptin concentrations were measured.

In contrast to the well-reported primary role for brown adipose tissue in thermoregulatory and diet-induced thermogenesis (Foster \& Frydman, 1979; Rothwell \& Stock, 1979, 1986), the part played by the liver in adaptive thermogenesis is quite obscure. In addition, our previous work has shown that liver metabolic activity is differently influenced by high-fat feeding and cold exposure. In fact,

\footnotetext{
Abbreviations: ME, metabolizable energy; $\mathrm{T}_{3}$, triiodothyronine.

* Corresponding author: Professor Giovanna Liverini, fax +390815424 848, email susiossa@unina.it
} 
increases in hepatic respiration have been found in hepatocytes isolated from rats exposed to cold or fed a high-fat diet (Iossa et al. 1991, 1997). However, hepatic mitochondrial NAD-linked oxidative capacities were upregulated by cold exposure (Iossa et al. 1991), and lowered by chronic dietary excess (Iossa et al. 1995). Therefore, to study the interactions between cold exposure and high-fat feeding on liver oxidative activity, we also evaluated changes in hepatic metabolism in rats fed a high-fat diet and exposed to cold. To this end, we assessed mitochondrial and peroxisomal respiration in a liver homogenate under different conditions of stimulation.

\section{Materials and methods}

\section{Animals and experimental design}

Male Wistar rats, obtained from Charles River (Calco, Como, Italy) just after weaning, were divided into five groups each composed of eight rats, with similar mean body weight (about $80 \mathrm{~g}$ ) and with body weight normally distributed within each group. They were individually housed in metabolic cages under an artificial circadian $12 \mathrm{~h}$ light-dark cycle (07.00-19.00 hours). The animals were allowed unrestricted access to food and water and their care, housing, and killing met the guidelines of the Italian Health Ministry.

One of the five groups of rats was killed at the onset to establish baseline measurements. Two of the remaining four groups of rats were housed at $24^{\circ} \mathrm{C}$ (control rats), while the other animals were maintained in a cold room at $4^{\circ} \mathrm{C}$ (cold-exposed rats). One group of control and cold-exposed rats was allowed a low-fat diet (Mucedola 4RF21; Settimo Milanese, Milan, Italy). The other group of control and cold-exposed rats was allowed a high-fat diet $(\mathrm{g} / \mathrm{kg})$ : lowfat diet 280, lyophilised meat 395, butter 178, alphacel 120 , AIN 76 vitamin mix 7, AIN 76 mineral mix 20. The composition (\% energy) of low-fat diet was: protein 29.0 , lipid 10.6, and carbohydrate 60.4. Calculated metabolizable energy (ME)/g low-fat diet was $12.50 \mathrm{~kJ}$. The composition (\% energy) of the high-fat diet was: protein $29 \cdot 0$, lipid 50.0, and carbohydrate $21 \cdot 0$. Calculated ME/g high-fat diet was $15 \cdot 80 \mathrm{~kJ}$. The high-fat diet supplemented with butter contains not only long-chain fatty acids but also mediumand short-chain fatty acids (about $10 \mathrm{~g} / 100 \mathrm{~g}$ ). In addition, the high-fat diet is characterised by the presence of a meat component, which is among the flavours most preferred by rats (Naim et al. 1985; Allard \& Le Blanc, 1988). Calculated ME of these diets was obtained from diet composition, applying the coefficient $(\mathrm{kJ} / \mathrm{g}) 15 \cdot 67,16 \cdot 72$, 37.62 , and 0 for carbohydrate, protein, fat, and fibre respectively. Diet and cold treatment lasted 2 weeks. We chose an experimental period of 2 weeks because it is long enough to elicit adaptive responses to the high-fat diet and cold and allows us to isolate diet and cold effects from the confounds of growth.

Body weight, food intake, and body gains in energy, fat and
protein

Throughout the experimental period body weights and food intakes were monitored daily to allow calculations of bodyweight gain and gross energy intake. Spilled food was collected and accounted for in the food intake calculations. Faeces and urine were also collected on a daily basis. ME intake was obtained by subtracting energy content of the faeces and urine from gross energy intake, which was calculated by multiplying cumulated intakes of each diet by the respective energy density. The gross energy density of the diets (low-fat diet $15.88 \mathrm{~kJ} / \mathrm{g}$, high-fat diet $19.85 \mathrm{~kJ} / \mathrm{g}$ ), as well as that of the faeces and urine, was determined by a bomb calorimeter calibrated with dry benzoic acid standard (Parr adiabatic calorimeter; Parr Instruments Co., Moline, IL, USA).

After 2 weeks of treatment, rats were starved during the last night-time feeding period. Next morning, rats were anaesthetised by intraperitoneal injection of chloral hydrate (400 mg/kg body weight) and blood and liver were collected. The carcasses were then weighed, autoclaved for $90 \mathrm{~min}$, chopped into small pieces, thoroughly mixed, and finally homogenised with water (volume equal to twice the carcass weight) in a Polytron homogeniser (Polytron Kinematica AG, Littau/Lucerne, Switzerland). Aliquots of the homogenates were desiccated at $70^{\circ} \mathrm{C}$ in a vacuum oven. Small pellets (about $200 \mathrm{mg}$ ) of the dried homogenate were made and the body energy content was measured with the bomb calorimeter. Corrections were made for the energy content of the liver, which was taken for determination of in vitro respiration rate. To this end, aliquots of liver were dried and energy content was measured with the bomb calorimeter. Aliquots of the carcass homogenate were analysed for water, lipid and protein content. Water content was determined by the difference in weight of the homogenate before and after drying at $70^{\circ} \mathrm{C}$ in a vacuum oven. Lipid content was determined gravimetrically after extraction in chloroformmethanol and evaporation to constant weight by a rotating evaporator (Heidolph, Kelheim, Germany) by the method of Folch et al. (1957). The energy as lipid was calculated from the lipid content by using the coefficient of $39.2 \mathrm{~kJ} / \mathrm{g}$ for the energy content of lipid. Protein content was determined by the Biuret method after extraction in SDS-NaOH as described by Brooks et al. (1995). The energy as protein was calculated from the protein content by using the value of $23.5 \mathrm{~kJ} / \mathrm{g}$ for the energy content of protein. Body energy gain was calculated by subtracting the energy content of the rats that were killed at the beginning of the experiment from that of each of the four experimental groups. Energy expenditure was calculated from the difference between ME intake and energy gain.

\section{Preparation of homogenates}

Before livers were removed, they were freed of blood by in situ perfusion. The portal vein was cannulated and perfusion was performed using $150 \mathrm{ml}$ of a cold solution of $220 \mathrm{mM}$-mannitol, $70 \mathrm{mM}$-sucrose, $20 \mathrm{mM}-$ Hepes, $\mathrm{pH}$ 7.4, $1 \mathrm{mM}$-EDTA, and $1 \mathrm{~g}$ fatty acid free bovine serum albumin/l. Livers were then removed, blotted and weighed, and aliquots were taken for energy content determination. The remainder of the tissue was finely minced and gently homogenised with the same medium $(1: 10, w / v)$ in a Potter 
Elvehjem homogenizer (Heidolph) set at $500 \mathrm{rpm}$ (4 strokes/min). The resulting homogenate was used directly for respiration measurements. The use of homogenate allows us to link mitochondrial oxidative capacities with the effective mitochondrial protein mass.

\section{Polarographic measurement of respiration}

Mitochondrial $\mathrm{O}_{2}$ consumption was estimated by a Clarktype electrode (Yellow Springs Instruments, Yellow Springs, OH, USA). It was maintained in a water-jacketed chamber at $37^{\circ} \mathrm{C}$. Aliquots of the homogenate were added to $3 \mathrm{ml}$ respiratory medium, which consisted of $80 \mathrm{mM}-$ $\mathrm{KCl}, 50$ mM-Hepes, pH 7.0, 5 mM- $\mathrm{KH}_{2} \mathrm{PO}_{4}, 1$ mM-EGTA, $1 \mathrm{~g}$ fatty acid free bovine serum albumin/l. First, measurements of $\mathrm{O}_{2}$ consumption were carried out with a respiratory substrate $(10 \mathrm{mM}$ succinate $+3.75 \mu \mathrm{m}$ rotenone, or $10 \mathrm{mM}$-glutamate $+2.5 \mathrm{mM}$-malate, or $40 \mu \mathrm{M}$ palmitoyl-carnitine $+2.5 \mathrm{mM}$-malate), followed by ADP (at a final concentration of $0.3 \mathrm{mM}$ ). The $\mathrm{O}_{2}$ consumption increased, corresponding to the ATP synthesis-coupled respiration (state 3 respiratory rate) (Chance \& Williams, 1956). Then, $\mathrm{O}_{2}$ consumption was measured only with ADP at the above concentration. $\mathrm{O}_{2}$ consumption without added substrates was subtracted from that in the presence of respiratory substrates to determine mitochondrial respiration.

Peroxisomal $\mathrm{O}_{2}$ consumption was measured polarographically at $37^{\circ} \mathrm{C}$ according to Inestrosa et al. (1979). Aliquots of homogenate were added to respiratory medium which consisted of $100 \mathrm{mM}-$ Tris, $\mathrm{pH} 8 \cdot 3,5 \mathrm{mM}-\mathrm{KCN}$, $200 \mu \mathrm{M}-\mathrm{NAD}, 50 \mu \mathrm{M}-\mathrm{FAD}, 0 \cdot 1 \mathrm{mM}-\mathrm{CoA}, 6 \mathrm{~g}$ fatty acid free bovine serum albumin/l. The reaction was started with $35 \mu \mathrm{M}$-palmitoyl-CoA. Determinations were made in the dark to avoid the photochemical consumption of $\mathrm{O}_{2}$ catalysed by FAD.

\section{Serum free triiodothyronine and leptin level}

Blood was collected via the inferior cava vein. Serum samples were stored at $-20^{\circ} \mathrm{C}$ until the time of analysis. Serum free $T_{3}$ was measured using radioimmunoassay kit
(Coat A Count; Diagnostic Production Corporation, Los Angeles, CA, USA). Serum leptin was determined using a radioimmunoassay kit obtained from Mediagnost (Tubingen, Germany). Each hormone was measured in a single assay to remove inter-assay variations.

\section{Statistical analysis}

Data are given as means with their standard errors for eight different rats per group. Statistical analyses were performed by two-way ANOVA for the main effects of diet and environmental temperature as well as for the interaction effect between diet and environmental temperature. Regression analyses were also performed. Probability values less than 0.05 were considered to indicate a significant difference. All analyses were performed using GraphPad Prism (GraphPad Software, San Diego, CA, USA).

\section{Materials}

$\mathrm{ADP}, \mathrm{NAD}, \mathrm{FAD}, \mathrm{CoA}$, malate, glutamate, succinate, rotenone, palmitoyl-carnitine, palmitoyl-CoA were purchased from Sigma Chemical Co., St Louis, MO, USA. All other reagents used were of the highest purity commercially available.

\section{Results}

Table 1 shows body and liver weight, as well as body energy and composition. The body-weight gain of coldexposed rats was significantly lower than that of control rats, while it was not affected by high-fat feeding. Despite the significant decrease in final body weight found in coldexposed rats compared with controls, liver weight did not change. Consequently, the relative liver weights ( $\mathrm{g}$ liver $/ \mathrm{kg}$ body weight) significantly increased in cold-exposed rats compared with controls. In addition, cold-exposed rats significantly decreased their body energy and percentage body lipid compared with controls. However, no significant effects of diet nor diet $\times$ temperature interactions were observed.

Table 1. Body weight and composition in control or cold-exposed rats fed a low-fat or high-fat diet for 2 weeks (Mean values with their standard errors for eight rats per group)

\begin{tabular}{|c|c|c|c|c|c|c|c|c|c|c|c|}
\hline & \multicolumn{4}{|c|}{ Control } & \multicolumn{4}{|c|}{ Cold exposed } & \multirow{2}{*}{\multicolumn{3}{|c|}{$\begin{array}{c}\text { Statistical significance } \\
\text { of difference between } \\
\text { means (ANOVA): } P\end{array}$}} \\
\hline & \multicolumn{2}{|c|}{ Low fat } & \multicolumn{2}{|c|}{ High fat } & \multicolumn{2}{|c|}{ Low fat } & \multicolumn{2}{|c|}{ High fat } & & & \\
\hline & Mean & SE & Mean & SE & Mean & SE & Mean & SE & $\mathrm{D}$ & $\mathrm{T}$ & $\mathrm{D} \times \mathrm{T}$ \\
\hline Initial body weight (g) & 80 & 5 & 80 & 3 & 80 & 1 & 80 & 2 & NS & NS & NS \\
\hline Final body weight (g) & 168 & 2 & 173 & 3 & 124 & 10 & 130 & 4 & NS & $<0.0001$ & NS \\
\hline Body-weight gain (g) & 88 & 3 & 93 & 3 & 44 & 9 & 50 & 4 & NS & $<0.0001$ & NS \\
\hline Liver weight (g) & $8 \cdot 5$ & 0.2 & $8 \cdot 0$ & 0.1 & $8 \cdot 0$ & 0.4 & $8 \cdot 9$ & 0.4 & NS & NS & NS \\
\hline Liver weight/body weight (\%) & $5 \cdot 0$ & 0.1 & $4 \cdot 6$ & 0.1 & 6.5 & 0.2 & $6 \cdot 8$ & $0 \cdot 2$ & NS & $<0.0001$ & NS \\
\hline Body water $(\mathrm{g} / \mathrm{kg})$ & 683 & 30 & 696 & 30 & 733 & 30 & 733 & 30 & NS & NS & NS \\
\hline Body lipid (g/kg) & 128 & 14 & 125 & 8 & 51 & 6 & 59 & 6 & NS & $<0.0001$ & NS \\
\hline Body protein $(\mathrm{g} / \mathrm{kg})$ & 131 & 11 & 147 & 3 & 158 & 2 & 151 & 4 & NS & NS & NS \\
\hline Body energy (kJ/g) & $8 \cdot 3$ & 0.7 & $8 \cdot 5$ & 0.4 & 5.9 & 0.2 & $6 \cdot 1$ & 0.3 & NS & $<0.0001$ & NS \\
\hline
\end{tabular}

$\mathrm{D}$, main effect of diet; $\mathrm{T}$, main effect of temperature; $\mathrm{D} \times \mathrm{T}$, interaction between diet and temperature.

${ }^{*}$ For details of diets and procedures see p. 90. 
Table 2. Energy balance in control or cold-exposed rats fed a low-fat or high-fat diet for 2 weeks* (Mean values with their standard errors for eight rats per group)

\begin{tabular}{|c|c|c|c|c|c|c|c|c|c|c|c|}
\hline & \multicolumn{4}{|c|}{ Control } & \multicolumn{4}{|c|}{ Cold exposed } & \multirow{2}{*}{\multicolumn{3}{|c|}{$\begin{array}{c}\text { Statistical significance } \\
\text { of difference between } \\
\text { means (ANOVA):P }\end{array}$}} \\
\hline & \multicolumn{2}{|c|}{ Low fat } & \multicolumn{2}{|c|}{ High fat } & \multicolumn{2}{|c|}{ Low fat } & \multicolumn{2}{|c|}{ High fat } & & & \\
\hline & Mean & SE & Mean & SE & Mean & SE & Mean & SE & D & $\mathrm{T}$ & $\mathrm{D} \times \mathrm{T}$ \\
\hline ME intake (kJ) & 3298 & 60 & 4424 & 118 & 3954 & 141 & 4182 & 183 & $<0.001$ & $<0.05$ & $<0.01$ \\
\hline Energy expenditure (kJ) & 2420 & 128 & 3470 & 153 & 3739 & 88 & 3905 & 182 & $<0.01$ & $<0.001$ & $<0.01$ \\
\hline Body energy gain (kJ) & 878 & 40 & 954 & 42 & 215 & 16 & 277 & 27 & NS & $<0.0001$ & NS \\
\hline Protein gain $(\mathrm{kJ})$ & 265 & 30 & 342 & 36 & 211 & 20 & 212 & 12 & NS & $<0.05$ & NS \\
\hline Lipid gain $(\mathrm{kJ})$ & 596 & 54 & 601 & 42 & 0 & 5 & 54 & 10 & NS & $<0.0001$ & NS \\
\hline Protein gain/protein intake (\%) & 29.0 & 0.3 & 28.0 & 0.3 & $17 \cdot 0$ & 0.2 & $20 \cdot 0$ & 0.2 & NS & $<0.01$ & NS \\
\hline Lipid gain/lipid intake (\%) & 171 & 2 & 27 & 1 & 0 & 1 & 3 & 1 & $<0.0001$ & $<0.0001$ & $<0.001$ \\
\hline
\end{tabular}

$\mathrm{ME}$, metabolizable energy; $\mathrm{D}$, main effect of diet; $\mathrm{T}$, main effect of temperature; $\mathrm{D} \times \mathrm{T}$, interaction between diet and temperature.

* Values refer to the whole period of the diet treatment (2 weeks). For details of diets and procedures see p. 90.

In Table 2, ME intake and energy expenditure are reported together with body energy, protein, and lipid gain. Relative to the group fed the low-fat diet at $24^{\circ} \mathrm{C}$, both energy intake and expenditure were increased in the group fed the high-fat diet or by cold exposure. However, in the group fed the high-fat diet and exposed to cold concomitantly, no further increases in energy intake nor in energy expenditure were observed. Body energy, protein, and lipid gain significantly decreased in cold-exposed rats compared with controls. Table 2 also shows that the percentage of ingested lipid and protein which was stored as carcass energy significantly decreased in coldexposed rats compared with control rats. A significant decrease in the percentage of ingested lipid stored as carcass energy was found in control rats fed the high-fat diet compared to those fed the low-fat diet.

Table 3 shows partitioning of ME intake and the values obtained for energy expenditure excluding the total cost of storage called net energy expenditure. The total cost of storage was determined taking into account that the energy loss in storing $1 \mathrm{~kJ}$ protein is $1.25 \mathrm{~kJ}$ (Pullar \& Webster, 1977). The corresponding energy cost for fat deposition is $0 \cdot 36 \mathrm{~kJ} / \mathrm{kJ}$ for diets with a high percentage of carbohydrate (Pullar \& Webster, 1977), such as the low-fat diet, and $0 \cdot 16 \mathrm{~kJ} / \mathrm{kJ}$ for diets with a high-fat content, such as the high-fat diet (Rothwell et al. 1985). Net energy expenditure, both as absolute values and as percentage of $\mathrm{ME}$ intake, was significantly higher in cold-exposed rats than in controls. On the other hand, the body energy gain and cost of storage, both expressed as percentage of ME intake, significantly decreased in cold-exposed rats compared with controls. Finally, lipid and protein gain expressed as percentage of $\mathrm{ME}$ intake decreased in cold-exposed rats compared with controls.

Fig. 1 shows daily energy intake and expenditure expressed per metabolic body size $\left(\mathrm{kg}^{0.75}\right)$ of the experimental groups. In cold-exposed rats fed the low-fat diet, we found increases in both ME intake and energy expenditure compared with control rats fed the low-fat diet. In coldexposed rats fed the high-fat diet both ME intake and energy expenditure were slightly higher than those of coldexposed rats fed the low-fat diet and control rats fed the high-fat diet. In addition, in cold-exposed rats, ME intake and energy expenditure tended to approach each other, whereas in control rats daily ME intake values strongly exceeded energy expenditure.

Mitochondrial respiratory capacities were measured in liver homogenate using NAD- and FAD-linked substrates and are reported in Table 4. Rats fed the high-fat diet showed a significant decrease in NAD-linked respiration, while no significant variation was found with FAD-linked or lipid substrate. Both NAD- and FAD-linked respiration was significantly increased in cold-exposed rats compared with controls. Table 4 also shows that no variation was found in peroxisomal fatty acid oxidation capacity.

The serum levels of free $\mathrm{T}_{3}$ and leptin, as well as the correlation between leptin and body lipid mass in

Table 3. Partitioning of metabolizable energy intake in control or cold-exposed rats fed low-fat or high-fat diet for 2 weeks* (Mean values with their standard errors for eight rats per group)

\begin{tabular}{|c|c|c|c|c|c|c|c|c|c|c|c|}
\hline & \multicolumn{4}{|c|}{ Control } & \multicolumn{4}{|c|}{ Cold exposed } & \multirow{2}{*}{\multicolumn{3}{|c|}{$\begin{array}{c}\text { Statistical significance } \\
\text { of difference between } \\
\text { means (ANOVA): } P\end{array}$}} \\
\hline & \multicolumn{2}{|c|}{ Low fat } & \multicolumn{2}{|c|}{ High fat } & \multicolumn{2}{|c|}{ Low fat } & \multicolumn{2}{|c|}{ High fat } & & & \\
\hline & Mean & SE & Mean & SE & Mean & SE & Mean & SE & $\mathrm{D}$ & $\mathrm{T}$ & $\mathrm{D} \times \mathrm{T}$ \\
\hline NEE (kJ) & 1874 & 189 & 2947 & 157 & 3475 & 52 & 3631 & 193 & $<0.01$ & $<0.01$ & $<0.05$ \\
\hline NEE/ME intake (\%) & $56 \cdot 0$ & 0.5 & $65 \cdot 8$ & 0.6 & 89.0 & 1.9 & $85 \cdot 1$ & 1.7 & $<0.01$ & $<0.01$ & $<0.01$ \\
\hline Body energy gain/ME intake (\%) & $26 \cdot 7$ & $2 \cdot 0$ & $21 \cdot 8$ & $2 \cdot 0$ & $5 \cdot 0$ & $1 \cdot 0$ & $7 \cdot 3$ & $1 \cdot 0$ & $<0.01$ & $<0.01$ & $<0.01$ \\
\hline Cost of storage/ME intake (\%) & $17 \cdot 3$ & $2 \cdot 3$ & $12 \cdot 4$ & 0.4 & $6 \cdot 0$ & 0.5 & $7 \cdot 6$ & 0.6 & $<0.01$ & $<0.01$ & $<0.01$ \\
\hline Protein gain/ME intake (\%) & 8.6 & 1.5 & $8 \cdot 2$ & 0.2 & $5 \cdot 0$ & 0.4 & 5.9 & 0.4 & NS & $<0.01$ & NS \\
\hline Lipid gain/ME intake (\%) & $18 \cdot 1$ & $2 \cdot 7$ & $13 \cdot 6$ & 1.3 & 0.0 & 1.0 & 1.4 & $0 \cdot 1$ & $<0.01$ & $<0.01$ & $<0.01$ \\
\hline
\end{tabular}

NEE, net energy expenditure excluding the total cost of storage; ME, metabolizable energy; $\mathrm{D}$, main effect of diet; $\mathrm{T}$, main effect of temperature; $\mathrm{D} \times \mathrm{T}$, interaction between diet and temperature.

*Values refer to the whole period of the diet treatment (2 weeks). For details of diets and procedures see p. 90. 

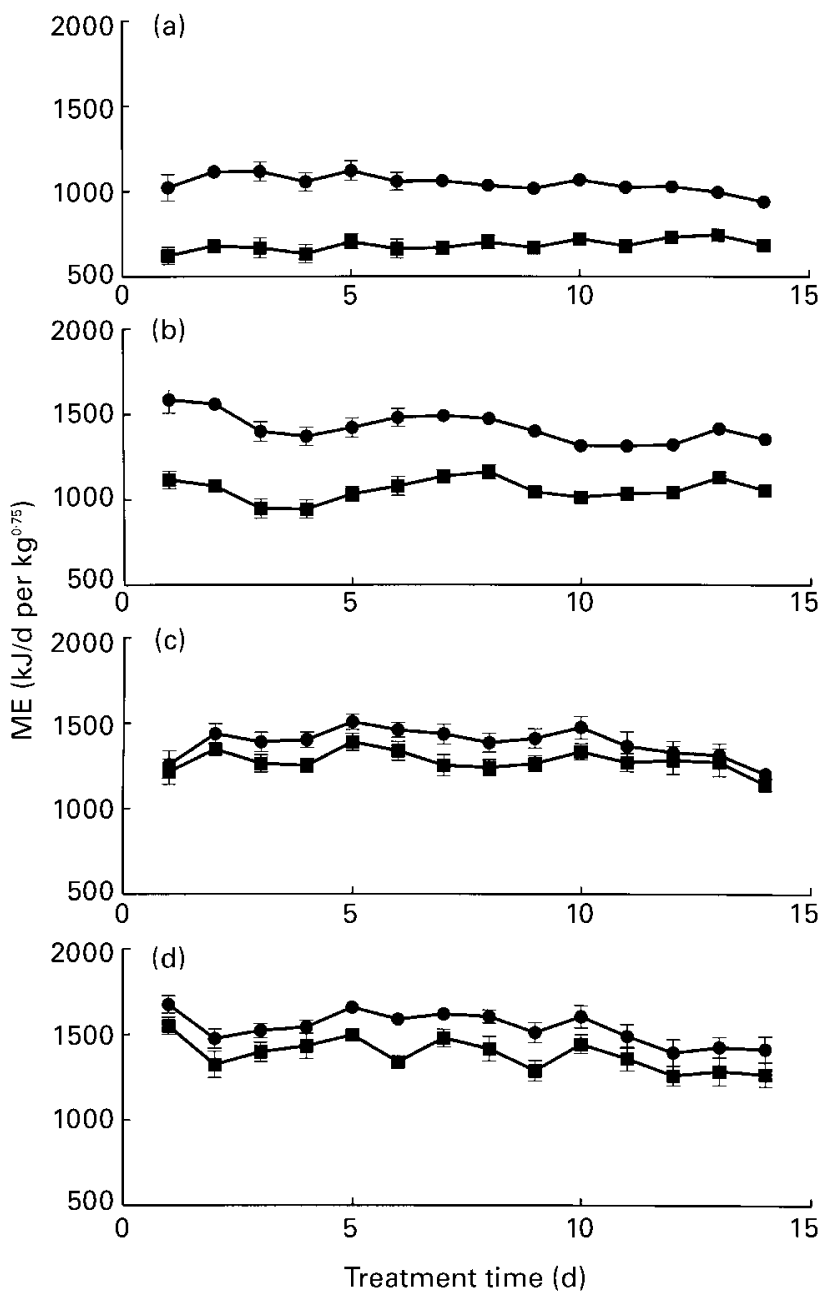

Fig. 1. Daily metabolizable energy (ME) intake $(\bullet)$ and energy expenditure ( $\mathbf{\square})$ for control rats fed a low-fat (a) or high-fat diet (b) or cold-exposed rats fed low-fat (c) or high-fat diet (d) throughout the experimental period of 2 weeks. For details of diets and procedures see p. 90. Values are means for eight rats per group with standard errors shown by vertical bars.

cold-exposed or control rats fed the two experimental diets are reported in Fig. 2. Cold exposure significantly increased serum free $\mathrm{T}_{3}$ levels. In addition, rats fed the high-fat diet exhibited higher levels of serum free $T_{3}$ than
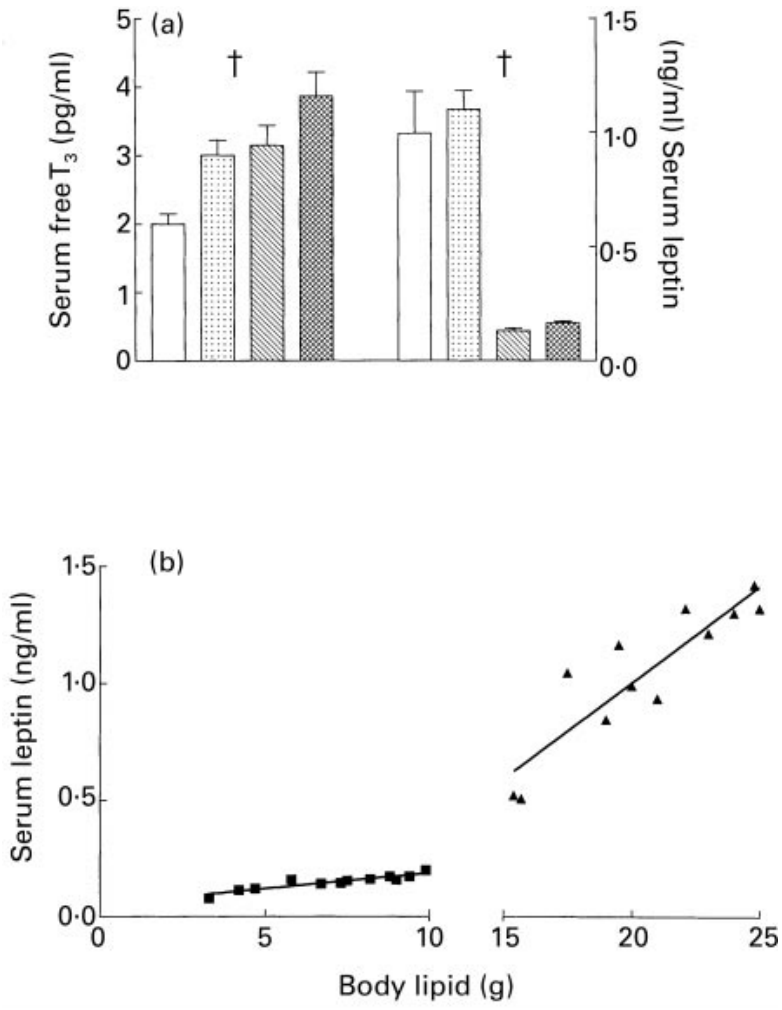

Fig. 2. (a) Serum free triiodothyronine $\left(T_{3}\right)$ and leptin levels and (b) correlation between serum leptin levels and body lipid mass in control or cold-exposed rats fed a low-fat or high-fat diet after the experimental period of 2 weeks. For details of diets and procedures see p. 90. (a), Values are means for eight $\left(T_{3}\right)$ or six (leptin) rats per group with standard errors shown by vertical bars. $\square$, Control low fat; 国, control high fat; $\mathbb{\mathbb { }}$, cold low fat, $\otimes$, cold high fat. (b), Each point represents individual value. $\mathbf{0}$, Cold $\left(r^{2} 0.844, P<0.0001\right) ; \boldsymbol{\Delta}$, control $\left(r^{2} 0.809, P<0.0001\right)$. *Main effect of diet $(P<0.05)$; †main effect of temperature $(P<0.05)$.

those of rats fed the low-fat diet. As for serum leptin levels, they drastically decreased in cold-exposed rats compared with control rats. In these rats, serum leptin levels were significantly positively correlated with body-fat mass $(P<$ 0.0001). Cold-exposed rats exhibited a similar significant relationship $(P<0 \cdot 0001)$, although the slope of regression line was significantly different from that found in control rats $(P<0 \cdot 001)$.

Table 4. Mitochondrial and peroxisomal oxidative capacity in liver homogenate from control or cold-exposed rats fed low-fat or high-fat diet for 2 weeks*

(Mean values with their standard errors for eight rats per group)

\begin{tabular}{|c|c|c|c|c|c|c|c|c|c|c|c|}
\hline & \multicolumn{4}{|c|}{ Control } & \multicolumn{4}{|c|}{ Cold exposed } & \multirow{2}{*}{\multicolumn{3}{|c|}{$\begin{array}{c}\text { Statistical significance } \\
\text { of difference between } \\
\text { means (ANOVA): } P\end{array}$}} \\
\hline & \multicolumn{2}{|c|}{ Low fat } & \multicolumn{2}{|c|}{ High fat } & \multicolumn{2}{|c|}{ Low fat } & \multicolumn{2}{|c|}{ High fat } & & & \\
\hline & Mean & SE & Mean & SE & Mean & SE & Mean & SE & $\mathrm{D}$ & $\mathrm{T}$ & $\mathrm{D} \times \mathrm{T}$ \\
\hline \multicolumn{12}{|l|}{ Mitochondrial oxidative capacity } \\
\hline Glutamate + malate + ADP & 2900 & 102 & 2340 & 60 & 5276 & 120 & 5258 & 70 & $<0.01$ & $<0.01$ & $<0.01$ \\
\hline Palmitoyl-carnitine + malate + ADP & 5250 & 213 & 4730 & 290 & 6336 & 289 & 6086 & 465 & NS & $<0.01$ & NS \\
\hline $\begin{array}{l}\text { Succinate }+ \text { rotenone }+ \text { ADP } \\
\text { Peroxisomal oxidative capacity }\end{array}$ & 9100 & 1031 & 9300 & 837 & 14176 & 567 & 13532 & 672 & NS & $<0.01$ & NS \\
\hline Palmitoyl-CoA & 450 & 27 & 440 & 39 & 449 & 31 & 381 & 38 & NS & NS & NS \\
\hline
\end{tabular}

$D$, main effect of diet; $T$, main effect of temperature; $D \times T$, interaction between diet and temperature.

* Oxidative capacity was expressed as $\mathrm{nmol} \mathrm{O} /(\mathrm{min} \times \mathrm{g}$ liver $)$. For details of diets and procedures see p. 90. 


\section{Discussion}

The results of this present work clearly indicate that cold exposure and high-fat feeding induced similar changes in energy intake associated with alterations in energy expenditure and fuel partitioning. On the other hand, cold exposure but not high-fat feeding increased the mitochondrial oxidative capacity of the liver.

Present results on body composition and energy balance obtained in control rats fed the high-fat diet are in agreement with our previous studies (Iossa et al. 1997; Mollica et al. 1999). These experimental data have been repeated here to evaluate the effect of cold or diet in the cold-exposed rat fed a high-fat diet. Both cold exposure and high-fat feeding increased daily ME intake and energy expenditure from the first day, and the increase was maintained over the whole period of the experimental treatment (Fig. 1). In addition, net energy expenditure, which can represent the cost of the body energy maintenance, significantly increased in the cold-exposed rats, but this increase was not completely balanced by hyperphagia, with a following decrease in body lipid and energy content (Table 1). Our results also show that in cold-exposed rats, protein and fat gain was lower than that expected based on energy intake and lipid content of the diets. In fact, when lipid and protein gain were expressed as a percentage of lipid and protein intake respectively, significantly lower values were obtained in cold-exposed rats compared with controls. Since similar results were previously obtained in control rats fed a high-fat diet (Mollica et al. 1999), it appears that cold exposure and a high-fat diet improve the ability to utilise fat as metabolic fuel, thus counteracting obesity development. The increased lipid oxidative capacity could be in part due to the presence in our high-fat diet of short- and mediumchain fatty acids, which have been shown to stimulate thermogenesis (Papamandjaris et al. 1998). Different results have been obtained using high-fat diets composed only of long-chain fatty acids. In fact, an increase in body fat was found both in rats reared at room temperature (Hansen et al. 1997; Widdowson et al. 1997) and exposed to cold (Goubern et al. 1988). Therefore, in human nutrition, the potential impact of dietary fat composition on metabolism and body-weight regulation should be considered.

Since it is well known that $T_{3}$ increases food intake and energy expenditure (Abelenda \& Puerta, 1991; Iossa et al. 1992), serum levels of free $T_{3}$ have been measured. We have found an increase in the circulating levels of free $T_{3}$ in response to a high-fat diet and cold exposure, in agreement with previous results (Goglia et al. 1983; Iossa et al. 1995). Cold-exposed rats fed the high-fat diet exhibited the highest $\mathrm{T}_{3}$ levels (Fig. 2), indicating that cold exposure and a highfat diet, when given together, do not interact but rather their effects seem to be additive. The increased serum free $T_{3}$ levels are consistent with the variations found in body energy gain:ME intake and net energy expenditure:ME intake ratios (Table 3), suggesting that the enhanced circulating $\mathrm{T}_{3}$ levels could be involved in the adaptive response induced by cold exposure and high-fat feeding. In addition, thyroid hormones are known to stimulate fatty acid oxidation capacity (Oppenheimer et al. 1991) and could, therefore, be involved in the increased lipid utilisation of rats exposed to cold or fed a high-fat diet.

We also investigated the circulating hormone leptin, which is involved in the regulation of body weight by signalling the size of energy stores in adipose tissue (Friedman, 1998). In the control rats, there were no significant changes in serum leptin levels depending on dietary fat content (Fig. 2), in agreement with the finding that rat fed the low-fat or high-fat diet exhibited similar body lipid content. In contrast, in cold-exposed rats leptin levels fell by a significant amount (about ten-fold). Bing et al. (1998) showed a lower (50-60 \%) reduction in leptin levels after 8 and $21 \mathrm{~d}$ cold exposure. One possible explanation for this different finding could be the age of the rats. In fact, the rats used by Bing et al. (1998) were older than those in the present study and therefore could be less sensitive to cold stress. In agreement, Bing et al. (1998) found a lower increase in energy intake $(10 \% v$. $20 \%$ in the present study) and unchanged leptin:body fat correlation in cold-exposed rats. Here we show that circulating leptin levels were positively correlated with lipid mass both in control and cold-exposed rats, although the regression line obtained in control rats was significantly different from that obtained in cold-exposed rats $(P<$ 0.001). This result indicates that the fall in leptin levels found in cold-exposed rats is due not only to decreased body fat stores but also to other factors. For example, the increased sympathetic activity which occurs during cold exposure (Barney et al. 1980), may contribute to the fall in leptin levels. In fact, leptin production is negatively regulated by the sympathetic nervous system, which suppresses $o b$ gene transcription via $\beta_{3}$ adrenoceptors ( $\mathrm{Li}$ et al. 1997; Evans et al. 1999). The decrease in leptin concentrations could contribute to hyperphagia via neuropeptide Y (Friedman, 1998), which is a potent stimulator of food intake (Stanley \& Leibowitz, 1984). However, it has been found recently that in cold-exposed rats there were no increases in hypothalamic neuropeptide $\mathrm{Y}$ or neuropeptide Y mRNA (Bing et al. 1998). It could be suggested that hyperphagia in cold-exposed rats can be driven by high levels of circulating $T_{3}$ found in these rats.

To study liver oxidative response to the combination of thermogenetic stimuli, namely cold exposure and high-fat feeding, we have measured mitochondrial and peroxisomal respiration in liver homogenates so that direct information on whole-tissue oxidative capacity can be obtained. In control rats, high-fat feeding significantly reduces NADlinked mitochondrial respiratory rates, without any variation in FAD-supported oxidative capacity. These results are in agreement with previous findings on isolated mitochondria (Iossa et al. 1995; Lionetti et al. 1996a) and our suggestion of a fall in hepatic metabolic efficiency due to a shift in hepatic respiration from NAD-linked to FAD-linked pathways (Iossa et al. 1995). A decreased tissue metabolic efficiency appears to be a characteristic response to high-fat feeding, since increased inefficiency has also be found in brown adipose tissue (Rothwell \& Stock, 1979, 1986) and skeletal mass (Matsuda et al. 1997) in rats fed a high-fat diet. However, the mechanisms involved in metabolic inefficiency at the level of different tissues seem to be 
different and as yet undefined. In cold-exposed rats mitochondrial respiratory rate and hence ATP production significantly increased compared with controls (Table 4). The increase in ATP synthesis capacity is more substantial if we consider the concomitant increase in the relative liver weight (g liver/kg body weight) and is consistent with the increase in hepatic gluconeogenesis which occurs in coldexposed rats (Shiota et al. 1985). In view of the important role of glucose as fuel for the increased metabolic activity of brown adipose tissue and skeletal mass during cold exposure (Vallerand et al. 1990), the increased hepatic metabolism is central in response to cold stress. In addition, in cold-exposed rats fed the high-fat diet, high-fat feeding does not reverse the effect of cold exposure on liver oxidative capacity probably because cold induces prevention of obesity per se. A similar effect has been shown in skeletal muscle in which cold exposure reverses the diabetogenic effect of high-fat feeding by improving glucose uptake (Vallerand et al. 1986). On the other hand, high-fat feeding and cold exposure exert similar and additive effects on brown adipose tissue thermogenic capacity (Rothwell \& Stock, 1980). From our present results it appears that cold-exposure activates mitochondrial ATP synthesis in liver, whereas high-fat feeding probably induces decreased hepatic efficiency as a means for wasting excess ingested food energy. These differences in the liver response to the thermogenic stimuli are most probably due to the hormonal pathways involved. In fact, a study of Young \& Landsberg (1979) indicated that the turnover rate of liver noradrenaline was not affected by cold exposure, but markedly increased during overfeeding. In addition, the presence of specific leptin receptors in liver (De Matteis et al. 1998; Nemecz et al. 1999) suggests that leptin plays a direct role in this organ.

In summary, in young Wistar rats, a high-fat diet and cold exposure increased the body capacity to utilise energy. On the other hand, the liver response to cold exposure was different to that of high-fat feeding. The response to cold exposure, namely increased oxidative activity, occurs also when the two stimuli are given together.

\section{Acknowledgement}

This work was supported by Ministero dell'Università e della Ricerca Scientifica e Tecnologica of Italy.

\section{References}

Abelenda M \& Puerta ML (1991) Relationship among food intake, thyroid state, and chronic cold-exposure in the rat Hormone and Metabolic Research 23, 90-91.

Allard M \& Le Blanc J (1988) Effect of cold acclimation, cold exposure, and palatability on postprandial thermogenesis in rats. International Journal of Obesity 12, 169-178.

Barney CC, Katovich MJ, Fregly MJ \& Tyler PE (1980) Changes in $\beta$-adrenergic responsiveness of rats during chronic cold exposure. Journal of Applied Physiology 49, 923-929.

Bing C, Frankish HM, Pickavance L, Wang Q, Hopkins DFC, Stock MJ \& Williams G (1998) Hyperphagia in cold-exposed rats is accompanied by decreased plasma leptin but unchanged hypothalamic NPY. American Journal of Physiology 274, R62R68.
Brooks SPJ, Lampi BJ, Sarwar G \& Botting HG (1995) A comparison of methods for determining total body protein. Analytical Biochemistry 226, 26-30.

Chance B \& Williams GR (1956) The respiratory chain and oxidative phosphorylation. Advances in Enzymology 17, 65134.

Danforth E \& Burger AG (1989) The impact of nutrition on thyroid hormone physiology and action. Annual Review of Nutrition 9, 201-227.

De Matteis R, Dashtipour K, Ognibene A \& Cinti S (1998) Localisation of leptin slice variants in mouse peripheral tissues by immunohistochemistry. Proceedings of Nutrition Society $\mathbf{5 7}$, $441-448$

Evans BA, Agar L \& Summers RJ (1999) The role of the sympathetic nervous system in the regulation of leptin synthesis in C57BL/6 mice. FEBS Letters 444, 149-154.

Folch J, Lees M \& Stanley GHS (1957) A simple method for the isolation and purification of total lipides from animal tissues. Journal of Biological Chemistry 226, 497-510.

Foster DO \& Frydman ML (1979) Tissue distribution of cold induced thermogenesis in conscious warm- or cold-acclimated rats re-evaluated from changes in tissue blood flow: the dominant role of brown adipose tissue in the replacement of shivering by nonshivering thermogenesis. Canadian Journal of Physiology and Pharmacology 57, 257-270.

Freake HC \& Oppenheimer JH (1995) Thermogenesis and thyroid function. Annual Review of Nutrition 15, 263-291.

Friedman JM (1998) Leptin, leptin receptors, and the control of body weight. Nutrition Reviews 2, S38-S46.

Friedman JM \& Halaas JL (1998) Leptin and the regulation of body weight in mammals. Nature 395, 763-770.

Goglia F, Liverini G, De Leo T \& Barletta A (1983) Thyroid state and mitochondrial population during cold exposure. Pflügers Archive-European Journal of Physiology 396, 49-53.

Goubern M, Laury MC, Razanoelina M \& Portet R (1988) Effect of environmental temperature on dietary obesity in OsborneMendel rats. Annals of Nutrition and Metabolism 32, 340-346.

Hansen PA, Han DH, Nolte LA, Chen M \& Holloszy JO (1997) DHEA protects against visceral obesity and muscle insulin resistance in rats fed a high-fat diet. American Journal of Physiology 273, R1704-R1708.

Inestrosa NC, Bronfman M \& Leighton F (1979) Detection of peroxisomal fatty acyl-Coenzyme A oxidase activity. Biochemical Journal 182, 779-788.

Iossa S, Lionetti L, Mollica MP, Barletta A \& Liverini G (1999) Fat balance and hepatic mitochondrial function in response to fat feeding in mature rats. International Journal of Obesity 23, $1122-1128$.

Iossa S, Lionetti L, Mollica MP, Crescenzo R, Barletta A \& Liverini G (2000) Effect of long-term high-fat feeding on energy balance and liver oxidative activity in rats. British Journal of Nutrition (In the Press).

Iossa S, Mollica MP, Lionetti L, Barletta A \& Liverini G (1995) Hepatic mitochondrial respiration and transport of reducing equivalents in rats fed an energy dense diet. International Journal of Obesity 19, 539-543.

Iossa S, Mollica MP, Lionetti L, Barletta A \& Liverini G (1997) Energy balance and liver respiratory activity in rats fed on an energy-dense diet. British Journal of Nutrition 77, 99-105.

Iossa S, Liverini G \& Barletta A (1991) Physiological changes due to cold adaptation in rat liver. Cellular Physiology and Biochemistry 1, 226-239.

Iossa S, Liverini G \& Barletta A (1992) Relationship between the resting metabolic rate and hepatic metabolism in rats: effect of hyperthyroidism and fasting for 24 hours. Journal of Endocrinology 135, 45-51.

Li H, Matheny M \& Scarpace PJ (1997) $\beta_{3}$-Adrenergic-mediated 
suppression of leptin gene expression in rats. American Journal of Physiology 272, E1031-E1036.

Lionetti L, Iossa S, Brand MD \& Liverini G (1996a) Relationship between membrane potential and respiration rate in isolated liver mitochondria from rats fed an energy dense diet. Molecular and Cellular Biochemistry 158, 133-138.

Lionetti L, Iossa S, Brand MD \& Liverini G (1996b) The mechanism of stimulation of respiration in isolated hepatocytes from rats fed an energy-dense diet. Nutritional Biochemistry 7, $571-576$.

Luz J \& Griggio MA (1987) Effect of food intake on oxygen consumption in cold-acclimated rats. Brazilian Journal of Medical and Biological Research 20, 619-622.

Matsuda J, Hosoda $\mathrm{K}$, Itoh $\mathrm{H}$, Son $\mathrm{C}$, Doi $\mathrm{K}$, Tanaka $\mathrm{T}$, Fukunaga Y, Inoue G, Nishimura H, Yoshimasa Y, Yamori Y \& Nakao K (1997) Cloning of rat uncoupling protein-3 and uncoupling protein- 2 cDNAs: their gene expression in rats fed high-fat diet. FEBS Letters 418, 200-204.

Mollica MP, Iossa S, Liverini G \& Soboll S (1999) Stimulation of oxygen consumption following addition of lipid substrates in liver and skeletal muscle from rats fed a high-fat diet. Metabolism 48, 1230-1235.

Naim M, Brand JG, Kare MR \& Carpenter RG (1985) Energy intake, weight gain, and fat deposition in rats fed nutritionally controlled diet in a multichoice ("cafeteria") design. Journal of Nutrition 115, 1447-1458.

Nemecz M, Preininger K, English R, Fürnsinn C, Schneider B, Waldhäusl W \& Roden M (1999) Acute effect of leptin on hepatic glycogenolysis and gluconeogenesis in perfused rat liver. Hepatology 29, 166-172.

Oppenheimer JH, Schwartz HL, Lane JT \& Thompson MP (1991) Functional relationship of thyroid hormone-induced lipogenesis, lipolysis, and thermogenesis in the rat. Journal of Clinical Investigation 87, 125-132.

Papamandjaris AA, MacDougall DE \& Jones PJH (1998) Medium chain fatty acid metabolism and energy expenditure: obesity treatment implications. Life Sciences 62, 1203-1215.

Pullar JD \& Webster AJF (1977) The energy cost of fat and protein deposition in the rat. British Journal of Nutrition 37, 355-363.
Rothwell NJ \& Stock MJ (1979) A role for brown adipose tissue in diet-induced thermogenesis. Nature 281, 31-35.

Rothwell NJ \& Stock MJ (1980) Similarities between cold- and diet-induced thermogenesis in the rat. Canadian Journal of Physiology and Pharmacology 58, 842-848.

Rothwell NJ \& Stock MJ (1982) Energy expenditure of "cafeteria-fed" rats determined from measurements of energy balance and indirect calorimetry. Journal of Physiology 382, $371-377$.

Rothwell NJ \& Stock MJ (1986) Brown adipose tissue in dietinduced thermogenesis. In Brown Adipose Tissue, pp. 269-286 [P Trayhurn and DG Nicholls, editors]. London: Edward Arnold.

Rothwell NJ, Stock MJ \& Warwick BP (1985) Energy balance and brown fat activity in rats fed cafeteria diets or high-fat, semisynthetic diets at several levels of intake. Metabolism 34, 474-480.

Shiota M, Tanaka T \& Sugano T (1985) Effect of norepinephrine on gluconeogenesis in perfused livers of cold-exposed rats. American Journal of Physiology 249, E281-E489.

Stanley BG \& Leibowitz SF (1984) Neuropeptide Y injected into hypothalamus: a powerful neurochemical inducer of hyperphagia and obesity. Proceedings of the National Academy of Science, USA 82, 3940-3943.

Vallerand AL, Lupien J \& Bukowiecki LJ (1986) Cold exposure reverses the diabetogenic effects of high-fat feeding. Diabetes 35, 329-334.

Vallerand AL, Perusse F \& Bukowiecki LJ (1990) Stimulatory effects of cold exposure and cold acclimation on glucose uptake in rat peripheral tissues. American Journal of Physiology 259, R1043-R1049.

Widdowson PS, Upton R, Buckingham R, Arch J \& Williams G (1997) Inhibition of food response to intracerebroventricular injection of leptin is attenuated in rats with diet-induced obesity. Diabetes 46, 1782-1785.

Young JB \& Landsberg L (1979) Effect of diet and cold exposure on norepinephrine turnover in pancreas and liver. American Journal of Physiology 236, E524-E533. 